\title{
LA GUERRA EN UN NOVELISTA “DESHUMANIZADO”: LA NOVELA PÓSTUMA DE BENJAMÍN JARNÉS
}

\author{
A la memoria de mi abuelo, Cándido Juárez, a \\ quien no conocí, muerto en el Hospital de san- \\ gre de Quintanar de la Orden en noviembre \\ de 1936.
}

\section{Luis A. Esteve Juárez*}

RESUMEN: En este trabajo, tras pasar revista a la fortuna editorial y crítica de Jarnés, se analizan algunos de los aspectos de Su línea de fuego, (1980): personajes, espacio, elementos discursivos, etc. poniéndolos en relación con otros textos jarnesianos (anteriores, simultáneos y posteriores). Esta revisión permite clarificar su actitud en aquel momento: frente a la agresión de la "segunda barbarie", el deber de defenderse, pero sin odio ni exaltaciones partidistas ni personales. Esta actitud y la fidelidad a su propia estética y ética -no buscar solución al problema del dolor humano "será dejar de ser hombre"-iban a ser mal comprendidas y Jarnés, muy lúcidamente, ya lo señalaba en Cartas al Ebro. Así fue. Cayeron sobre él los tópicos -apoliticismo, deshumanización y frivolidad-que aún se repiten. Por ello se hace necesaria la revisión que en este artículo se plantea.

ABSTRACT: This article, after having reexamined Jarnés's volumes chance and critical misfortune as a novelist, analyzes some of the aspects of the novel Su línea de fuego (1980): characters, background, discursive components, etc. and their relationship with some other Jarnés's texts (being previous, simultaneous and even later to Su línea de fuego). Re-examining allows the article's author to clarity Jarnés's attitude towards the Spanish Civil War: to the "segunda barbarie" aggression, he opposes the duty of defending from it, but without hate nor political or personal extremism. Jarnés's attitude and loyalty to his own ethics and aesthetics -not to try to give an answer to human's pain "será dejar de ser hombre"-was not understood and he was aware of it as he points out lucidly in his Cartas al Ebro. Commonplaces as apolitical, deshumanized and frivolous attitude are still repeated about Jarnés; therefore the necessary reexamination that this brief article proposes.

\section{Barcelona.}

* Catedrático de lengua y literatura española en el Instituto de Bachillerato Infanta Isabel de Aragón. 
El nombre de Benjamín Jarnés es conocido porque una breve referencia, imprescindible a la hora de tratar la prosa vanguardista, se halla incluso en los manuales de historia literaria. Sin embargo, sigue siendo un ilustre desconocido al haber sufrido un largo silencio editorial ${ }^{1}$. De hecho sigue en el limbo, pues a los lectores actuales no les es accesible a excepción de algunas biografías reeditadas en Austral ${ }^{2}$, o de las ediciones zaragozanas de los años $80^{3}$ a las que debemos añadir la reciente aparición de Viviana y Merlín 4 y Locura y muerte de Nadie 5 . Las positivas valoraciones críticas de Ayala, Gullón, Mainer e incluso Nora ${ }^{6}$ no han tenido la misma repercusión que algunos tópicos muy difundidos. Tópicos que tienen su punto de partida en algunos desafortunados juicios de críticos de gran predicamento ${ }^{7}$, así como el menosprecio que

1. V. aún Domingo Ródenas, "Renovación del canon: Revisión de la narración vanguardista", Insula 594, (Junio 1996), pp. 8-10. Jordi Gracia, "La difícil vigencia de Benjamín Jarnés”, en Insula 594, (Junio 1996), pp. 10-11. En ambos artículos se señalan algunas novedades bibliográficas referidas al período más estrictamente vanguardista.

2. Castelar. Hombre del Sinaí, Madrid, Espasa-Calpe (Austral, 1431), 1971; Sor Patrocinio. La monja de las llagas, Madrid, Espasa-Calpe (Austral, 1497), 1972; Zumalacárregui. El caudillo romántico, Madrid, Espasa-Calpe (Austral, 1511), 1972; Doble agonía de Bécquer, Madrid, Espasa-Calpe (Austral, 1521), 1973. Se refiere específicamente a este hecho E. de Zuleta, Arte y vida en la obra de Benjamín Jarnés, Gredos (BRH, II Est. y Ens., 267), Madrid, 1977, p. 11. También José-Carlos Mainer en Benjamín Jarnés, El convidado de papel, Ed. Guara (Nueva Bibl. de Autores Aragoneses), Zaragoza, 1979. Prólogo de --, pág. 9. Son cuatro biografías publicadas por la misma Espasa en los años 30 en su colección "Vidas Españolas e Hispanoamericanas del siglo XIX", inspirada por Ortega, y en la que colaboraron autores tan dispares como Pío Baroja, Antonio Espina, Juan Chabás, el mexicano Martín Luis Guzmán, Luis de Oteyza, o el conde de Romanones. Algunas de ellas fueron recuperadas en la citada Austral, como las de Romanones, Baroja o Espina, por ejemplo.

3. Son tres novelas en la desaparecida Editorial Guara: la citada en n. 1; Lo rojo y lo azul, Guara (Nueva Bibl. Autores Aragoneses), Zaragoza, 1981, prólogo de Francisco Ayala; y Su línea de fuego Guara (NBAA), Zaragoza, 1980. En 1988, la Inst. Fdo. el Católico con motivo del centenario publica los "Cuadernos Jarnesianos", que contienen material inédito, y varios estudios. Anteriormente, Cita de Ensueños, Ed. del Centro, Madrid, 1974.

4. Benjamín Jarnés, Viviana y Merlín, Cátedra (Letras Hispánicas, 317), Madrid, 1994. Ed. de Rafael Conte. Incluye las variantes de las dos ediciones y un extenso prólogo de gran interés pese a ciertas irregularidades.

5. Benajmín Jarnés, Locura y muerte de Nadie, Ed. Viamonte (Reencuentros, 1), Madrid, 1996. Introducción de Ildefonso Manuel Gil. Reproduce el texto de 1937 publicado por J. de Entrambasaguas en 1961.

6. J. C. Mainer, La Edad de Plata, Los libros de la Frontera 27, Barcelona 1975, 1ª , p. 251-255; A. Valbuena Prat, Historia de la Literatura Española III, G. Gili, Barcelona 1963, 7ª p. 712-715; E. G. de Nora, La novela española contemporánea II (1927-1939), Gredos (BRH, II Est. y Ens. 41), Madrid, 1973, $2^{\mathrm{a}}$, p. 155-192, con un balance positivo pese a su discrepancia estético-ideológica. A ellos se han de añadir los artículos de R. Gullón, Ildefonso M. Gil, E. de Zuleta (previo a su libro) o el "Prólogo" de Francisco Ayala a Lo rojo y lo azul y el ensayo de Manuel Andújar.

7. Max Aub, Manual de Historia de La Literatura Española, Akal, Madrid, 1974, p. 523; G. Torrente Ballester, Panorama de la Literatura Española Contemporánea I, Guadarrama (Panoramas II), Madrid, 1961, 2a , p.344-346; J. Chabás, Literatura Española contemporánea, Pueblo y Educación, La Habana, 1979, 2a , p. 569-573; M. Tuñón de Lara, Medio siglo de cultura española (1885-1936), Tecnos, Madrid, 1984, $3^{\text {a }}$ ed. reimp., p. 259-260; etc. 
sufrió la prosa vanguardista durante los años 50 por obvias razones de planteamiento estético-político 8 y del que únicamente alguno de aquellos prosistas ha conseguido evadirse a título individual y con bastante retraso. Sólo faltó que en los años sesenta Entrambasaguas en su reedición de Locura y muerte de nadie ${ }^{9}$ al mismo tiempo que valoraba positivamente la producción jarnesiana intentara una operación de asepsia ideológica afirmando que fue obligado a incorporarse al ejército republicano, pero que su participación fue meramente pasiva y que su producción literaria siguió el mismo rumbo sin acusar el cataclismo de la guerra, viniendo a reafirmar de este modo los juicios exclusivos procedentes del otro extremo del espectro ideológico.

En esta situación, en 1.980 se anunciaba en Insula ${ }^{10}$ el hallazgo de un cartapacio con varios textos de Jarnés entre ellos Su línea de fuego, una obra "perdida" en su doble versión: dialogada y novelesca. El mismo año, en plena euforia de una recuperación nunca acabada de la España Peregrina, aparecía la edición de Torregrossa y Hernández ${ }^{11}$ que pasó casi inadvertida. El texto que se nos ofrecía era parte de aquella "bibliografía fugitiva"12 de la que se conocían fragmentos ${ }^{13}$ e incluso había sido anunciada $^{14}$ como ocurre con Desierto profanado ${ }^{15}$. La importancia del hallazgo no pasaba desapercibida a los editores a pesar de que su análisis aún obedecía en algunos aspectos a una perspectiva resistencial.

Su línea de fuego ponía en entredicho aquellas afirmaciones: sí que había acusado literariamente el cataclismo de la guerra. Ciertamente, Jarnés al abordar el tema de la guerra civil lo pasa por el tamiz de su propia poética, pero ello no obsta para que su actitud quede clara: repulsa de la guerra y del dolor humano, defensa de la República

8. G. de Torre, “Una polémica sobre la 'deshumanización del arte'. Los puntos sobre las 'íes' novelísticas” en El fiel de la balanza, Taurus (Persiles 19), Madrid 1961, p. 69-82, en el que se encontrarán las referencias a los textos teórico-críticos de aquellos años.

9. J. de Entrambasaguas, "Prólogo" a Locura y muerte de Nadie, Las mejores novelas contemporáneas, VII. Planeta, Barcelona, 1961, p. 1313-1378. El interés de la edición radica en ser una versión ampliada, concluida en 1937.

10. Juan Ramón Torregrossa, "Su línea de fuego: novela inédita de Benjamín Jarnés sobre la guerra civil española”. Insula 403, Junio 1980, p. 4.

11. Benjamín Jarnés, Su línea de fuego, Guara Editorial, (Nueva Biblioteca de Escritores Aragoneses), Zaragoza 1980. Introducción y notas de Pascual Hernández del Moral y Juan Ramón Torregrosa. 188 págs. Los números entre [ ] remiten a las páginas de esta edición.

12. J. Domínguez Lasierra, Ensayo de una bibliografía jarnesiana Inst. Fernando el Católico, Zaragoza, 1988. p. 101.

13. Hora de España, XVI, abril 1938, Barcelona, p. 71-78. "Ruinas en España”. En nota a pie de página: "Introducción a la novela inédita "Su línea de fuego".

14. B. Jarnés, Cartas al Ebro, La Casa de España-FCE, México 1940, 1ª . En las págs. 221-2 hay una relación de las obras de Jarnés publicadas, y otra de pendientes de publicación: El convidado de papel

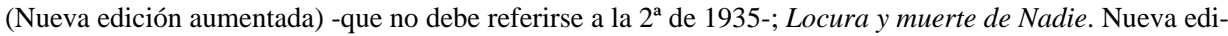
ción aumentada (En prensa.) -versión que Entrambasaguas publica en el volumen citado en n. 6-; Su línea de fuego. Novela. (En prensa.) -edición que no se realizó-; etc.

15. Benjamín Jarnés, Desierto profanado, Inst. Fdo. el Católico (Cuadernos Jarnesianos 4), Zaragoza, 1988. 
-deber muchas veces doloroso-, rechazo de las ideologías fascistas que imponen dictaduras y hacen surgir los peores instintos del hombre. Si el "apoliticismo" de Jarnés es la moneda que han intentado pasarnos los unos por restar un escritor significativo a la España Peregrina, los otros por no ser reductible a panfleto, el propio Jarnés lo desmiente:

"El enemigo estaba acechando y destruyó -jtemporalmente!- tu alegría, te ahogó en sangre, en la pólvora, en el embuste, en la blasfemia. Llegó a buscar la complicidad divina, todas las complicidades del cielo y la tierra para hacer ver que tu soberanía era de sainete, que la suya es drama en cinco actos, con endecasílabos, verdugos, patíbulos y campos de concentración.

[...] Pero el pueblo soberano -porque al fin ha de volver a serlo- escribirá el epílogo. Un epílogo digno de España, cuyos perfiles aún es imposible subrayar."16

En las líneas que siguen, mediante un breve recorrido por diversos aspectos de la novela -cuya existencia y planteamiento ha sido en general obviados por la críticaintentaremos clarificar cuál era la actitud de Jarnés, si verdaderamente fue un escritor de "escasa sensibilidad política"17 como aún se afirma.

La anécdota que sirve de soporte al relato, aunque de mayor entidad que en otras obras, sigue siendo sencilla. Mercedes, joven periodista belga, viaja a un hospital de retaguardia para ver a Narciso, piloto herido en combate y antiguo amante. Su intención es conseguir su recuperación física, psíquica y sentimental. Viaja acompañada de un marino, enamorado suyo sin esperanza y amigo de Narciso. En el hospital se encuentra con una condiscípula suya: la hija de los Condes de Monte Azul a la que sólo conoceremos por "Ofelia". Esta es un arquetípico "ángel de hospital" que oculta una espía que al ser descubierta se suicidará prefiriendo morir en aquel lugar, antiguo palacio rural de su familia convertido en "su línea de fuego". Mercedes consigue llevar a Narciso a un sanatorio suizo donde ella acaba su libro sobre la guerra de España y él, incapaz de aceptar su situación, se suicida.

Este asunto tan simple se enriquece notablemente al situar el espacio eje del relato y abordar el tema de la guerra civil desde una perspectiva infrecuente: la guerra sentida desde el mundo cerrado que supone el hospital, microcosmos en el que a través de unos pocos personajes podemos apreciar distintas actitudes ante la guerra, aunque no los episodios bélicos en sí mismos, porque, como dice el director del hospital a Mercedes, el pueblo español

16. Apud Manuel Andújar, "Benjamín Jarnés en galería de espejos” en Grandes Escritores Aragaoneses en la Narrativa Española del Siglo XX, Heraldo de Aragón, Zaragoza, 1981, p. 66-7. El texto procede de "El Rey", aparecido en Las Españas (febrero, 1950), revista dirigida por Andújar y Arana.

17. V. Jordi Gracia, art. cit., p. 10 (a). 


\section{LA GUERRA EN UN NOVELISTA “DESHUMANIZADO”:}

“... sólo llega a un acuerdo cuando se trata de desobedecer y no estaría mal que en las grandes ocasiones, en los desaforados trances históricos, se acordara de agruparse para todo lo contrario. De agruparse incondicionalmente... Porque, óigame bien, hasta la más necesaria disciplina se les antoja tiránica imposición. Y se pierden en hazañas personales, sin utilidad general, muchas veces. Por algo su historia, un famoso cronista la vio así, se reduce a episodios. Eso sí, frecuentemente geniales." [80-81]

En una alusión polisémica tanto a Galdós y a su genialidad, como a la inevitabilidad de tener que escribir aquellos episodios que reflejan hazañas tan individuales como inútiles. Y Jarnés nos irá presentando a los héroes anónimos como Antonio y otros heridos frente al individualismo egocéntrico de Narciso.

El procedimiento de localización es el habitual en Jarnés ${ }^{18}$ : uso de escenarios conocidos aunque transmutados de manera que permitan una cierta generalización -Augusta, los balnearios, Madrid19- aunque en este caso no procede de recuerdos lejanos sino próximos: la versión teatral previa estaba destinada a representarse en el hospital de sangre de Quintanar de la Orden donde Jarnés estuvo destinado y que acogía heridos procedentes del frente de Madrid ${ }^{20}$. Por otra parte la identificación del hospital con el palacio rural de los Monte Azul, escenario de las aventuras amorosas del conde [p. 95], remite a Locura y muerte de Nadie ${ }^{21}$. Es en esta finca de recreo, trasladada de las cercanías de Augusta a la Mancha, donde Juan Sánchez "Nadie" se entera de que es un bastardo de Monte Azul y una corista. Estamos ante otra constante de nuestro autor: la reutilización de materiales de una obra a otra ${ }^{22}$. El contraste que subraya el marino "Es que realmente tiene gracia la vida anterior de este inmueble [...] Parece que antes se perdía aquí la salud, mientras que hoy se recupera." [133] parece apuntar al necesario apartamiento de una aristocracia degradada y decadente, concretada en los Monte Azul.

El Prólogo -pieza siempre clave- transcurre en un castillo en ruinas -Ruinas en España se titulaba este fragmento en Hora de España-, cuyo valor simbólico se explicita en el mismo texto:

18. M Milar Martínez Latre, La novela intelectual de Benjamín Jarnés, Inst. Fdo. el Católico, Zaragoza 1979. Libro de obligada consulta, junto con el de Zuleta, para lo referente a la técnica y poética jarnesiana.

19. Ildefonso M. Gil, "Ciudades y paisajes aragoneses en las novelas de Benjamín Jarnés”, AFA, VI, 1956, p.87-114. tan útil y tan explotado por todos los estudiosos de Jarnés. Ampliado como "Espacios aragoneses en la obra de Benjamín Jarnés" se incluye en I. M. Gil, Escritores aragoneses (Ensayos y confidencias), Libr. General (Col. Aragón, 35), Zaragoza 1979.

20. Torregrossa, Art. Cit. en n. 8.

21. Locura y muerte de Nadie, ed. cit. en n. 6, p. 1476-1483.

22. Sobre la progresiva incorporación de elementos procedentes de obras anteriores, v. los libros cit. de E. de Zuleta, M ${ }^{\mathrm{a}}$ P. Martínez Latre y, además, V. Fuentes, Benjamín Jarnés: Bio-Grafía y metaficción, Inst. Fdo. el Católico, Zaragoza, 1988. 
“-Menos mal. Preferible es contemplar el castillo que se lleva dentro, porque el de fuera no puede tener menos gracia. La verdad es que a mí todo esto me parece bastante feo. [iEstas ruinas de España!

-Rectifique usted. No son ruinas de España, sino ruinas en España. Muchas cosas se están hoy en España arruinando... Pero no España.] Y este castillo sería probablemente muy feo, pero lo que queda de él es muy hermoso, precisamente por lo que falta." 23

El "Epilogo" en el "providente Sanatorio" -suizo naturalmente-, ofrece un irónico contraste por su asepsia, su ocultación del dolor convertida en negocio, con la actividad del Hospital de retaguardia. ¿Acaso con la elección de este escenario pretende dejar patente la indiferencia europea ante la tragedia que se estaba viviendo? Hasta la recuperación de la salud se convierte en "Empresa” [173].

Las referencias temporales internas son casi inexistentes. La acción puede transcurrir en un mes cualquiera del primer año de guerra y su duración es breve: queda acotada como al desgaire en boca del Mayordomo en el momento de la despedida de Narciso y el marino "Claro. Ocho días juntos..." [130]. Como en casi toda su novelística el tiempo concreto tiene relativa importancia al no ser la peripecia el único elemento constructivo determinante. Por otra parte, en breves flashes nos va dando noticia de los personajes, no sólo principales, sino también secundarios, como el soldado lector [140], auque en casos como éste resulten "motivos ciegos". Su valoración del tiempo novelesco queda reafirmada por el uso del presente histórico como tiempo dominante en el relato, lo que resulta coherente con las apelaciones al lector que va diseminando a lo largo de la novela.

El tratamiento de los personajes responde también a una constante jarnesiana: son pocos y responden a un papel aunque también ofrezcan rasgos de individualización. Dos mujeres destacan sobre el fondo: Mercedes la protagonista, y la hija de Monte Azul. Mercedes responde al tipo de mujer característico en Jarnés cuyos rasgos señala E. de Zuleta24: más fuerte que el personaje masculino, independiente y con capacidad de amar, acompañadas de la gracia -"vivaz escultura" [87]- y belleza:

"El la contempla unos instantes en silencio, embelesado. A ella ¡qué deprisa la fue transfigurando el tiempo! Toda su carne más firme, todo su espíritu más vivaz. Elegancia anatómica, sensibilidad alerta. En pocos minutos, ¡qué lección la de sus manos y la de todo su rostro! Suavidad en todo y todo suavidad." [85]

23. Hora de España, XVI, (abril 1938), Barcelona, p. 71-78. "Ruinas en España”. En nota al pie: "Introducción a la novela inédita "Su línea de fuego". El fragmento entre [ ] no aparece en Su línea de fuego, p.34- 35, sino en n. 2, p. 179, como variante del texto mecanográfico de 1938.

24. E. de Zuleta, op. cit., pág. 29-33, para la caracterización general, además de los estudios de personajes femeninos en novelas concretas o en "el género intermedio". V. también Ma P. Martínez Latre, op. cit., p. 231-5. 
La hija de Monte Azul carece incluso de nombre. El centinela-pedagogo la llama Ofelia anunciando su tragedia. Se trata de una joven desarraigada por su educación familiar cuya motivación es la venganza y el odio. Se ha afirmado que se la trata incluso con simpatía, pero más bien en su final lo que encontramos que despierta es la piedad de aquellos que por deber tienen que poner freno a su actividad. Su denuncia es un doloroso deber y la actitud del Director es la de la comprensión y piedad humanas, no muy lejos del espíritu que imbuía el discurso de Azaña que acababa con aquella exhortación: “¡Paz, piedad y perdón!”25.

De los masculinos, dos tienen nombre: Narciso el oponente de Mercedes, el héroe que incapaz de hacer frente a una vida cotidiana sin espectáculo se suicida; y Antonio, el pueblo, que cumple con su deber al tiempo que sufre su ceguera con gran estoicismo.

En una primera impresión parece que el autor adopta un punto de vista clásico matizado -como hemos apuntado- por el uso del presente histórico para dar una sensación de proximidad y observación inmediata. No es, sin embargo, así. Al señalar los escenarios hemos hecho referencia al "Prólogo" que nos sitúa en las ruinas de un castillo de la Mancha desde donde se divisa el Hospital. Allí dialogan Mercedes y el marino; y este diálogo tanto por su contenido como por su inesperado y, para ellos, invisible oyente, Cardenio el amante despreciado que abandona el mundo, nos introduce con suavidad en un mecanismo distanciador: la metaficción ${ }^{26}$. La anacrónica presencia de Cardenio, además de la ironía intertextual que supone, nos sitúa fuera del ámbito de un concepto de realismo ajeno a la estética jarnesiana. Pero además es un personaje recurrente 27 . En El convidado de papel $^{28}$, podemos encontrar una explicación de este personaje: Cardenio es Julio; Julio es Jarnés seminarista. ¿No será también este Cardenio el propio Jarnés? Probablemente, pues él mismo escribe: "Soy un Cardenio de la política. Sólo encuentro razones humanas para todo, no partidistas"29. El diálogo que oye Cardenio nos da ya una pauta de las ideas y actitudes de la novela: por boca de Mercedes Jarnés diagnostica "No, no son aquí los castillos, amigos del paisaje: pretenden ser sus dominadores. Los conozco. ¡A los castillos y a los hombres! He visto transeuntes harapientos, destrozados, cruzar altivamente la calle como caudillos triunfantes. Cuando no tienen a quien mandar mandan en su propia hambre." [37] 30 ; y propone la solución "Basta con hacerles aprender la gran lección del buen

25. M. Azaña, Discurso en el Ayuntamiento de Barcelona (18 de julio de 1938), en Obras Completas III, Giner, Madrid, 1990, p. 365-378, palabras finales.

26. V. Fuentes, op. cit., caps. II, IV y VI.

27. En 1934, estrena Cardenio, monodrama en la Sala Pleyel; Soledad de Cardenio, ensayo publicado en Las Españas, ap. Andújar, op. cit., p. 26. También en Locura y muerte de Nadie, ed. cit., p. ; y en El convidado de papel, v. n. 28.

28. Benjamín Jarnés, El convidado de papel, Guara (NBAA), Zaragoza 1979. Pról. de José C. Mainer. Cap. IV, Frag. 10, “Cardenio, el aturdido”, pp. 145-158.

29. Ap. V. Fuentes, op. cit., p. 19.

30. Es muy curioso el uso de esta expresión que da título a una novela del exilio: Isabel O. de Palencia, En mi hambre mando yo, Libro Mex (Temas Ibéricos), México 1959. 
ciudadano / republicana" [39 y 179, n. 7], que no es otra que "La libertad de un ciudadano acaba aquí donde comienza la libertad de otro ciudadano..." [39]. Otro elemento distanciador es la ironía a propósito de los procedimientos narrativos "Basta con un poco de técnica policíaca, de eso que suelen enseñar las novelas de gran éxito" [77], al mismo tiempo que nos puede invitar a acompañarle en la observación de algunas escenas: "El guiño de la enfermera nadie -excepto nosotros- puede advertirlo." [45] Tal apelación al lector -de larga tradición desde la épica- puede buscar varios efectos. El primero, la complicidad narrador / lector a través de ese plural inclusivo. Conseguida ésta, se elimina prácticamente la necesidad de referencias temporales explícitas, pues como espectadores directos percibiremos el fluir temporal. Al mismo tiempo esa presentación de las escenas puede producir cierto efecto cinematográfico nada ajeno a las preocupaciones del autor. Por último, al convertirnos en espectadores conscientes de nuestro papel no podemos identificarnos ya con los personajes aunque nos sintamos inclinados a la simpatía/compasión por cualquiera de ellos.

Sin embargo, es mayor el interés que despierta -como ya hemos señalado- la insólita perspectiva: al ubicarnos en ese microcosmos de forzada inactividad bélica, nos aleja de la exaltación épica al tiempo que nos sitúa en un punto de vista más propicio a la reflexión. Esta intención más reflexiva, se declara, como siempre, desde la "Introducción".

La guerra aparece aquí demasiado velada, demasiado pacífica. Por tanto, muy lejana de la cruda realidad histórica. Pero este fue el propósito del autor: atenuar, suavizar. [29] ${ }^{31}$

Reflexión y emoción es lo que se quiere transmitir:

"Ahora sólo se trata de recoger algunos rasgos, de esparcir algunas consideraciones de carácter general, con muy escaso valor de crónica; tal vez, eso sí, con algún valor emotivo y aún [sic] poético.” [29]

Quede la épica para otro momento. Al iniciar Desierto Profanado pasa revista a la literatura de guerra donde halla "mucho también, de cuanto suele acarrear la poesía en marcha"32 "Testimonio vivo" que un día más sereno permitirá la reconstrucción de la epopeya. Y no puede dejar de anotar la singularidad de aquella literatura escrita y con-

31. Palabras semejantes se leen en Desierto Profanado, ed. cit., p. 32: "Pero antes de continuar debemos advertir al lector que la guerra, aquí [por Desierto] aparecerá -voluntariamente- tal vez demasiado velada, demasiado 'pacífica'. Por tanto, muy lejana de toda la cruda realidad histórica. / Este fue precisamente el propósito del autor: atenuar, suavizar. No caprichosamente, sino con el fin de no agudizar más lo tan tremendamente agudizado para no oscurecer más lo tan pavorosamente oscuro. [...] / Un gran respeto al dolor humano - propio y ajeno-, mezclado a una firme voluntad de ser sincero y libre, han decidido al autor -a lo largo de todo el relato- a omitir cuidadosamente cualquier inútil imprecación,..."

32. Desierto Profanado, ed. cit., p. 7. 
sumida en las trincheras que recoge las más de las veces lo anecdótico que deberá ser integrado. En esta idea insiste en la nota que escribe sobre Madrid es nuestro ${ }^{33}$ de la que subrayaremos su indignación ante "caso tan abominable de inhibición" como el que presenta el mundo civilizado ante la gran tragedia española y el heroísmo de Madrid.

Ahora bien aquellas consideraciones serán expuestas no por uno o dos personajes como venía siendo habitual, sino por casi todos, porque cada uno es representativo de un sector, postura, grupo... Lo que no hay en ningún caso (se debe suavizar nos ha dicho) es una apología de la guerra, ni siquiera como defensa: simplemente, cada uno debe cumplir con su deber, el cual puede llegar a ser muy doloroso como es el caso de Antonio cuando informa al doctor de su descubrimiento o cuando éste informa a sus superiores de la identidad del espía -Ofelia- sabiendo cuál será el resultado. No hay odio ni desquite en ninguno de los dos. La emoción viene dada sobre todo por el estremecimiento ante el dolor, pero no el dolor humano en abstracto, sino el dolor de cada hombre concreto:

“-Mira... Ahí tienes un muchacho a quien una bomba dejó sin piernas y sin brazos.

-¡Qué horror! -dice el marino, llevándose instintivamente las manos a los ojos.

Y añade: ¿Por que no llevan estos restos humanos a las Cancillerías, a los Comités, a la Sociedad de Naciones? ¿Por qué?

$\cdots$

Que me cuenten a mí, ahora, unas teorías. Que se las cuenten, ahora, a ese infortunado tronco juvenil, totalmente podado de ramas. ... Aún le queda a ese despojo humano el cerebro... ¿Para qué? Para tormento suyo. ¿Qué podrá pensar, dime, de todos sus semejantes? ¿Qué podrá pensar de nosotros? [64]

Esta "amarga e implacable crítica" [144] -a partir de la visión estremecida de este antecedente del Johnny de Dalton Trumbo- está en la línea de otros textos jarnesianos en los que exponía su ideario estético y político y que fundamentan en buena medida una valoración ideológica, que no literaria, en la que se insiste en su apoliticismo y su elitismo, y el rechazo a la rebelión de las masas. Pero hay un breve ensayo que quizá sirva para aclarar la postura de Jarnés. Se trata del fragmento que corresponde al epígrafe de la "segunda barbarie" [143-145], motivo abordado anteriormente ${ }^{34}$. El fragmento aparecerá en boca del "pedagogo", observador al margen desde su puesto de centinela, graduado en la Escuela Normal, "profesor inútil" que sabe "manejar el

33. Benjamín Jarnés, Miguel de Unamuno. Antonio Machado y las masas. García Lorca. De Buffon y el estilo. Madrid. Inst. Fdo. el Católico (Cuadernos Jarnesianos, 7), Zaragoza 1988. pp. 51-54.

34. Locura y muerte de Nadie, ed. cit., pp. 1.512-1.513. 
máuser", trasunto del autor y portavoz de parte de sus reflexiones. Tras asistir a una conferencia con Antonio, el soldado ciego, le dice:

"-Estoy leyendo un libro que me prestó Juanita, esa enfermera que estudia leyes, donde he aprendido muchas cosas. Voy a leerte unas páginas.” [143]

Y lee un largo fragmento que es un ensayo sobre la crisis de autoridad y la suplantación de la misma por el mando de la mano de los dictadores, y tras unas consideraciones sobre la ¿mística? de los desfiles se pregunta: “¿Hemos llegado a los tiempos de la segunda barbarie, hace siglos profetizada por Juan Bautista Vico?" [144]. Para describir seguidamente como futuro lo que ya en 1.938 era el presente:

"Paisaje futuro: Rostros de mármol. Cascos de acero. Puños de hierro. Dureza de cara y gesto. Ninguna ternura humana. Movilización general de autómatas. El hombre convertido en maniquí... Y un hombre muy tieso que soporta docenas de desfiles, subiendo y bajando la mano; el autómata primero, el más complicado, el guía.

Y muchas frases orondas: ¡Están preñados de futuro! O esta otra: iSon el futuro plucuamperfecto! O ésta: ;El porvenir es nuestro! [144-5]

Donde no es difícil reconocer las imágenes que se difundían desde los servicios de propaganda fascistas o del Tercer Reich pues ¿quién si no va a ser ese "hombre muy tieso" que sube y baja la mano? ¿a qué retórica correspondían aquellas frases? Y aún añade: "No coloquéis ante la multitud en fiebre a un hombre leal a los hombres, poned un histrión." [145]. Que fuera Mussolini o Hitler o ambos queda a la imaginación del lector, pero conviene recordar la anécdota que recoge M. Andújar:

"En la Gran Vía barcelonesa, en las proximidades de la Secretaría de Propaganda, tiempos finales de la guerra civil. Se desencadenó un terrible bombardeo y al refugiarse Villegas en un portal coincidió, al cabo de larga falta de mutuas noticias, con Jarnés. Este, excepcionalmente exaltado, sin preámbulo alguno exclamó:

¡Yo estoy con la República! Soy judío, y por tanto enemigo del hitlerismo, que persigue a los de mi raza." 35

En resumen podríamos decir que el texto sitúa a unas multitudes enfebrecidas en la base de los regímenes fascistas y militaristas que se caracterizan por el ejercicio de un mando irracional. Ciertamente, en el texto se rastrean elementos orteguianos, especialmente la alusión a la crisis de autoridad, pero no aparece el vocablo "masas"36. A

35. M. Andújar, op. cit., p. 53.

36. Esto no quiere decir que no lo usara: Así, la motivación obsesiva de los actos de Juan Sánchez en Locura y muerte... es distinguirse, separarse de la masa; también en Cartas al Ebro, ed. cit. p. 161-2 o 195. 


\section{LA GUERRA EN UN NOVELISTA “DESHUMANIZADO”:}

este término prefiere Jarnés el de pueblo y popular [149] más en la línea de Machado cuya distinción entre masa y pueblo recoge y comenta en uno de sus cuadernos ${ }^{37}$.

Aún añadiremos otro fragmento, la "elegía al Parque del Oeste" 38 , en donde se evoca el asalto de Madrid en aquella noche de noviembre de 1.936 que no deja de aparecer en innumerables textos sobre la Guerra Civil, aquella noche en que se detuvo a las tropas rebeldes a las puertas de la entonces "capital de la gloria" -Alberti dixit-: con él.

“-Parque del Oeste -piensa-, ¿recuerdas bien la fecha? -y sigue hablando

Tú, el costado más sensible de Madrid, ¡con qué entereza soportaste la lanzada! Tú, el rostro más risueño de mi Madrid incomparable, ¿cómo pudiste recibir sin pestañear a tus verdugos?

Cruzaron por tu cuerpo destrozándolo, ultrajándolo, profanándolo, hasta llegar a clavar los dientes en la ciudad. ...

Parque del Oeste, ¿recuerdas bien la fecha?

Fecha límite, fecha espejo, fecha que divide en dos la historia española. Porque en ella se cuajó el gran silencio que salvó a Madrid.” [185]

La exaltación de los defensores de Madrid corre aparejada a la de los combatientes del Ebro "Cuando hace tres años veías retozar al hermanillo del Ebro, al Manzanares, ¿pensabas en que uno y otro alcanzarían la misma titánica grandeza?” [185]. Tras su lectura se me hace incomprensible que pueda seguir hablándose de la ambigüedad de Jarnés y más concretamente de nuestro texto.

Su línea de fuego no es una de las mejores obras de Jarnés, pero tampoco es deleznable. Como decían sus editores se trata de una novela "ejemplar", y lo es, con sus defectos y virtudes, por partida doble, primero por ese planteamiento explícito en el texto introductorio del autor, que se recoge con variantes en Desierto profanado y segundo porque al acogerse desde el Prólogo al patrocinio de Cervantes a través de Cardenio nos remite también a la ejemplaridad de las novelas cervantinas en las que "no hay ninguna de quien no se pueda sacar un ejemplo provechoso"39. Pero su interés mayor ahora radica en que contribuye juntamente cono los otros inéditos ya publicados a clarificar la postura política y -¿por qué no?- también estética de Jarnés en aquella coyuntura crítica y dramática.

Era de esperar que su aparición supondría una cierta revisión de afirmaciones como la de Chabás de que siguió escribiendo "sin aprovechar para nada, en su obra, las dramáticas experiencias que había vivido y sufrido" 40 . Pero no fue así. La primera

37. Miguel de Unamuno. Antonio Machado.., op. cit., pp. 25-27.

38. Es una de las variantes del texto mecanografiado de 1938. Su línea de fuego, ed. cit. p. 185-6. n. 7.

39. Para el idealismo y ejemplaridad de las Novelas ejemplares, especialmente las de la serie idealista, J. Casalduero, Sentido y forma de las Novelas Ejemplares, Gredos (BRH, II Est. y Ens. 57), Madrid 1962.

40. J. Chabás, op. cit., p. 570. 
reseña que se publica 41 tiene un tono francamente despectivo "drama abstracto", "simbolismo simplista", "visión intimista", limitándose a concederle un valor documental. Más equilibrados, los editores, no obstante reconocer su integridad personal, no dudan en situarlo ideológicamente entre aquellos intelectuales representantes de la pequeña burguesía que se muestran inquietos ante la "rebelión de las masas".

La celebración del centenario dio ocasión a un replanteamiento: publicación de inéditos, nuevos estudios. Señalaremos algunos. Nora despacha la novela en unas líneas muy simplistas para concluir afirmando que Jarnés acaba en la "cerrada perplejidad del 'ilustrado' que no comprende" 42 . Más interesante es el replanteamiento de V. Fuentes ${ }^{43}$ que realiza una lectura de Jarnés desde la "nueva crítica" viéndolo como un precursor de las postvanguardias y las nuevas corrientes estéticas y obviando curiosamente esta novela. Más ponderado, Mainer intenta centrar el problema de la concepción poética de Jarnés en su tiempo y señala que éste quería que "el arte no temiera contaminarse de la vida." 44 .

El problema de la valoración de Jarnés hunde sus raíces en los cambios que comienzan a producirse en la literatura europea de los años 30 a causa de la crisis general. Ya en aquellos años comienzan las polémicas ${ }^{45}$ entre los partidarios de una literatura comprometida, en muchos casos directamente militante, -como recuerda R. Conte ${ }^{46}$ siguiendo quizá inconscientemente los planteamientos de G. de Torre ${ }^{47}$ y aquellos que prefieren guardar su independencia estética e intelectual como Jarnés. A todo ello hay que añadir una unilateral interpretación del concepto orteguiano de "hombre-masa" y, por supuesto, de la tan traída y llevada "deshumanización del arte"48. En esta línea está buena parte de la crítica negativa basada en su actitud política que señalábamos al comenzar. Por un lado se le imputaba un apoliticismo propio de las vanguardias por no tomar una determinada opción partidista y por otro de una manera absolutamente incongruente se le encuadra en un sector ideológico pequeño-burgués de corte liberal-democrático semejante ¡al de Azaña! De esta visión partidista y maniquea debía de ser muy consciente el propio Jarnés cuando escribía "Postdata en 1.939" en Cartas al Ebro:

41. M. Batallón: "Reencuentro con un novelista aragonés", Andalán 287, (19 a 25 Septiembre 1980), p. 17.

42. Eugenio G. de Nora, "Unidad y evolución en la obra de Benjamín Jarnés”, en Jornadas Jarnesianas, Inst. Fdo. el Católico, Zaragoza, 1989, p. 86.

43. V. Fuentes, op. cit. en n. 18

44. José C. Mainer, “Creación y teoría literarias en Benjamín Jarnés”, en Jornadas Jarnesianas, cit., p. 122 .

45. César M. Arconada, “Quince años de literatura española”, Octubre, 1, Junio-Julio 1933, p. 7.

46. Rafael Conte, Intr. a Viviana y Merlín, ed. cit., pp. 40-41.

47. Guillermo de Torre, Doctrina y Estética literaria, Guadarrama, Madrid, 1970, p. 204-5, por ejemplo; o Historia de las literaturas de vanguardia, Guadarrama (Punto Omega, 117, 118, 119), Madrid, 1971, caps. 8 y 9 .

48. José C. Mainer, art. cit., Jornadas..., p. 116. 
"Excepcionalmente, más que ninguna otra, esa generación -la de Jean Giraudoux, la mía- ha sido zarandeada, fustigada...¿_Por qué? Por su carácter de risueña y audaz rebeldía. Por su carácter verdaderamente revolucionario. Porque la verdadera revolución es siempre heroica, y el heroísmo asusta al cobarde, al mal dotado... Por eso, todos los falsos demoledores la vinieron atacando, hasta llegar a proclamar el estado de estupidez literaria. [...]

Culpaban a esa generación de delitos de frivolidad, de inutilidad... Llegaron a reprocharle su alegría, signo de fortaleza, de gran ánimo..." 49

Esta convicción y la tragedia del destierro quizá expliquen la actitud de Jarnés a bordo del "Sinaia" 50 y que también se percibe en la melancólica amargura de Alta mar"s1.

Creemos que el vacío habitual en torno a Jarnés puede ser debido a un conjunto de factores. En primer lugar, su edad combinada con su origen social. Generacionalmente queda descolgado entre dos grupos o promociones con muy marcado carácter: la de Ortega y la del 27 por usar los marbetes más corrientes. Por otro lado, su biografía “y esto es más sutil, -como dice Mainer- lo sitúa extramuros de la cómoda instalación burguesa de los otros habitantes de la "nómina"" 52 . El segundo sería la fidelidad a sí mismo y su coherencia: lo que le censuran algunos cuando indican que no evoluciona desde sus primeros escritos, lo cual no es exacto, primero porque no conocen los verdaderamente primeros $^{53}$, segundo porque ya no es un jovenzuelo en sus primeros tanteos aunque, como muestra este texto póstumo, sí que la hubo pero no en el sentido que se pretendía. Por último, no debemos olvidar que su abundante producción en sus poco más de seis años de exilio ${ }^{54}$ es "pro panem lucrando" y que su relativamente temprana muerte le impidió desarrollar una serie de proyectos y esbozos $^{55}$ de los que no podemos prescindir a la hora de valorar esta etapa.

Volviendo a la novela que nos ocupa, quisiera recordar que, como en casi todas sus obras narrativas, nuestro autor nos explicita su propósito, que responde además a las anotaciones contenidas en Desierto Profanado y algún otro de los inéditos aparecidos. No apreciamos en ella una ruptura, pero sí una evolución técnica donde la trama cobra una mayor importancia aunque sin dejar que la intriga predomine sobre sus otros componentes habituales. ¿Se produce una cierta "humanización”? Quizá ya esta-

49. B. Jarnés, Cartas al Ebro, ed. cit. en n.14, p. 213.

50. M. Andújar, op. cit., pp. 55 y 67-68.

51. Benjamín Jarnés, Alta mar, Inst. Fdo. el Católico (Cuadernos Jarnesianos 6), Zaragoza, 1988. Es uno de los cuadernos inéditos y a él debe referirse Mada Carreño en Andújar, op. cit. 55 y ss.

52. J. C. Mainer, art. cit, Jornadas..., p. 111.

53. J. Domínguez Lasierra, op. cit., en n. 10. Puede verse una numerosa relación de escritos aparecidos en revistas de provincias de todo tipo.

54. J. Domínguez Lasierra, op. cit. Las producciones editoriales vienen reseñadas en la "Cronología”, pp. 19-20, mientras que libros propios y artículos se hallan en las secciones correspondientes.

55. Parte de ellos han sido editados en los mencionados "Cuadernos Jarnesianos", pero aún queda abundante material inédito en la Institución Fernando el Católico, al que debe sumarse lo recientemente depositado en la Residencia de Estudiantes. V. Jordi Gracia, art. cit. 
ba presente: baste recordar el texto de Ortega que figura al frente de Locura y muerte de Nadie 56 en el que leemos "La poesía y todo arte versa sobre lo humano y sólo sobre lo humano"; o la auténtica profesión de romanticismo que hallamos en la Introducción a su biografía de Bécquer, pero de un nuevo Romanticismo del siglo XX en el que el gran tema es el dolor "El gran problema del dolor humano está pidiéndonos urgentes soluciones. ... Desoír esa angustiosa voz será hacer profesión de inhumano. Será dejar de ser hombre" 57 . Palabras desde las que se ilumina la lectura de esta novela, la cual contribuye a debelar tópicos petrificados.

Palabras que escribía a principios de 1.936 Benjamín Jarnés, escritor a quien se le colgó el sambenito de frívolo y deshumanizado y a quien quisiéramos ver rescatado del panteón de "los raros", pues su lectura puede abrir una redonda perspectiva humana, vital y gozosamente imaginativa.

56. Locura y muerte..., ed. cit., p. 1383.

57. Doble agonía de Bécquer, Espasa (Austral 1521), Madrid 1973, p. 18. 